\title{
5 The question of stability: sigillata and 'Rhenish' wares between Lezoux and Trier (2nd-3rd centuries AD)
}

If the starting point of historical research is terra sigillata as a homogeneous, widespread category, as is the case in retrospective accounts, then the question of that category's stability never enters into the picture. Such stability is the necessary a priori to make the analysis work: one needs to assume that sigillata pots were the same thing always and everywhere in order to enter them into charts or distribution maps. The category is taken as 'ready-made', a historical given. Chapter 3 has shown how this starting point was actually the outcome of a situated process of negotiation and alignment of production practices, for example at Lezoux. Sigillata became defined as a homogeneous category, with a standardized package of traits, and clearly separate from other ceramic production sequences at the same site. Instead of undermining the kinds of big historical narratives that tend to be retrospectively built based on sigillata pots, this realization actually makes for advances in our use of terra sigillata for history-writing, as shown in chapter 4 with regard to the topics of trade and exchange (sigillata as history-teller). At the same time, it does justice to the role of sigillata itself in assuring smooth transitions between the different stages in its distribution chain (sigillata as history-maker).

But if we take seriously the notion that sigillata was only defined as a homogeneous category as the outcome of situated production practices at Lezoux, then it follows that this definition was subject to change. How could sigillata production at Lezoux remain a bounded, well-defined, and implicitly grasped kind of thing? This chapter looks into how the stability of production practices was maintained both at Lezoux and after transmission to another production site, Trier (Fig. 3.2).

It will do so through juxtaposing sigillata production with so-called 'Rhenish' wares (French céramiques métallescentes, German Schwarzfirnisware). First a note on vocabulary: the term 'Rhenish' wares is a historical misnomer, as examples were initially thought to have been produced exclusively in the Rhine area, but later discovered to have come from a wide range of ceramic centres in Central and East Gaul. In combination with considerable variability in the wares, this multiplicity of production sites is echoed by the fact that different scholars maintain different parameters for identifying 'Rhenish' wares: form, chronology, fabric, or surface finishing. ${ }^{530}$ The following discussion will emphasize patterns of mutual articulation between the production practices of sigillata and 'Rhenish wares'. Consequently the single term 'Rhenish' wares will be retained.

Finally, the jury is still out on the precise chronology of the period under study - the late 2nd century and first half of the 3rd century. The argument developed below thus stands insofar as its chronological anchors remain unchallenged. Nevertheless, even if the specificities of the interpretation are open to reformulation on a chronological basis, the key conceptual and methodological arguments of this chapter (in particular the defining relationship between sigillata and 'Rhenish' wares, the changes this underwent, and their implications) hold true nonetheless.

530 Brulet/Symonds/Vilvorder 1999. 


\section{I B O U N D A R Y W O R K : S I G I L L A T A A N D 'R H E N I H' W A R E A T L E Z O U X}

5. I. I PRODUCTION OF FINE WARES AT LEZOUX, MID 2 ND CENTURY

Based on the current state of evidence 'Rhenish' wares are likely to have originated around the middle of the 2nd century in Central Gaul and more specifically at Lezoux. ${ }^{531}$ One criterion for dating is stylistic comparison with decorative styles on moulded sigillata ${ }^{532}$, which testifies to the close interaction between these new 'Rhenish' wares and the by then established 'category' of sigillata. To understand this relation, we first need to ask which other products sigillata production had entered into a dialogue with.

So-called 'black sigillata' had pronounced similarities (calcareous clays, forms, decoration) to sigillata, but differed from the latter in colour and forms (liquid containers). The most common sigillata forms are as yet unknown in black sigillata (e.g. Drag. 37, 30, 18/31, 33). ${ }^{533}$ On the other hand, no forms were unique to black sigillata, in contrast to the later 'Rhenish' wares. ${ }^{534}$ This functional divergence can in turn be interpreted as a rapprochement between black sigillata and another product whose production was dwindling by the start of the 2nd century: colour-coated wares (French céramiques engobées). Fairly short-lived at Lezoux (from the middle of the 1st until the start of the 2nd century), these comprised a range of drinking beakers with non-calcareous clays and non-sintered coatings, resulting from mode A firing (reducing firing, oxidizing cooling). ${ }^{535}$ Black sigillata seems to have mediated the functional and technical boundaries between sigillata and colour-coated wares, with several of its technological choices cross-referencing both production sequences. It is tempting to see the later 'Rhenish' wares as taking up this role of mediator, but the fate of colour-coated wares in the first half of the 2 nd century remains poorly documented. ${ }^{536}$

The thriving centre for all of these products was the Maringues group, driving the early 2nd century process of experimentation in sigillata production. ${ }^{537}$ 'Rhenish' ware production has been attested in slightly higher numbers at the Saint Taurin group, associated with the phase of standardisation of sigillata towards the middle of the 2nd century. Once sigillata had become a bounded 'category', other products would have been 'Othered' ${ }^{538}$, in a conceptual and practical sense. The production sequence of sigillata was kept separate from that of other ceramic products - from clay fetching to firing - so that any other product clearly fell outside of this sequence and was entirely 'other' to it.

The spatial (same workshop group) and temporal (mid 2nd century) overlap between the stabilization of sigillata production as a 'category' and the start of 'Rhenish' ware production hints at close daily contacts between potters producing one or both kinds of pottery. 'Rhenish' wares contained in the kilns or deposits unearthed so far were always mixed with larger numbers of sigillata. ${ }^{539}$ Little is known about workshop organisation and infrastructure, whether there was a differentiation in structural lay-out, and to what extent the chaine opératoire of these different products led to day-to-day encounters in the taskscape. It is probably not too far-fetched to imagine regular interaction, for instance during breaks or meals.

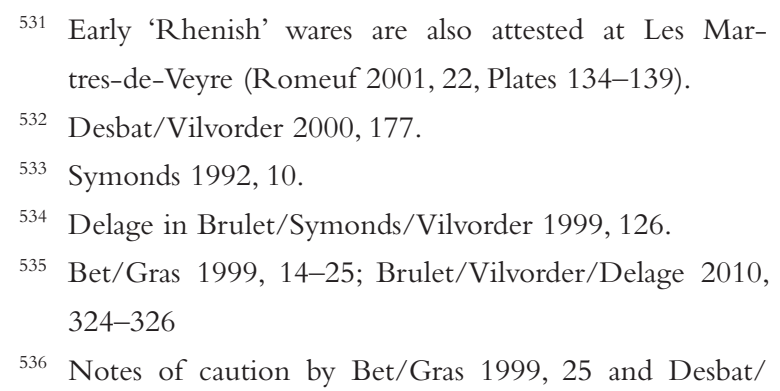

Vilvorder 2000, 177

537 See section 3.4.

538 This terminology alludes to Said 1978. For ANT, see Bloomfield/Vurdubakis 1999; Munro 1997. For a critique that ANT does not leave space for an 'Other', see Lee/Brown 1994; Star 1991.

539 Bet/Gras 1999, 35. 


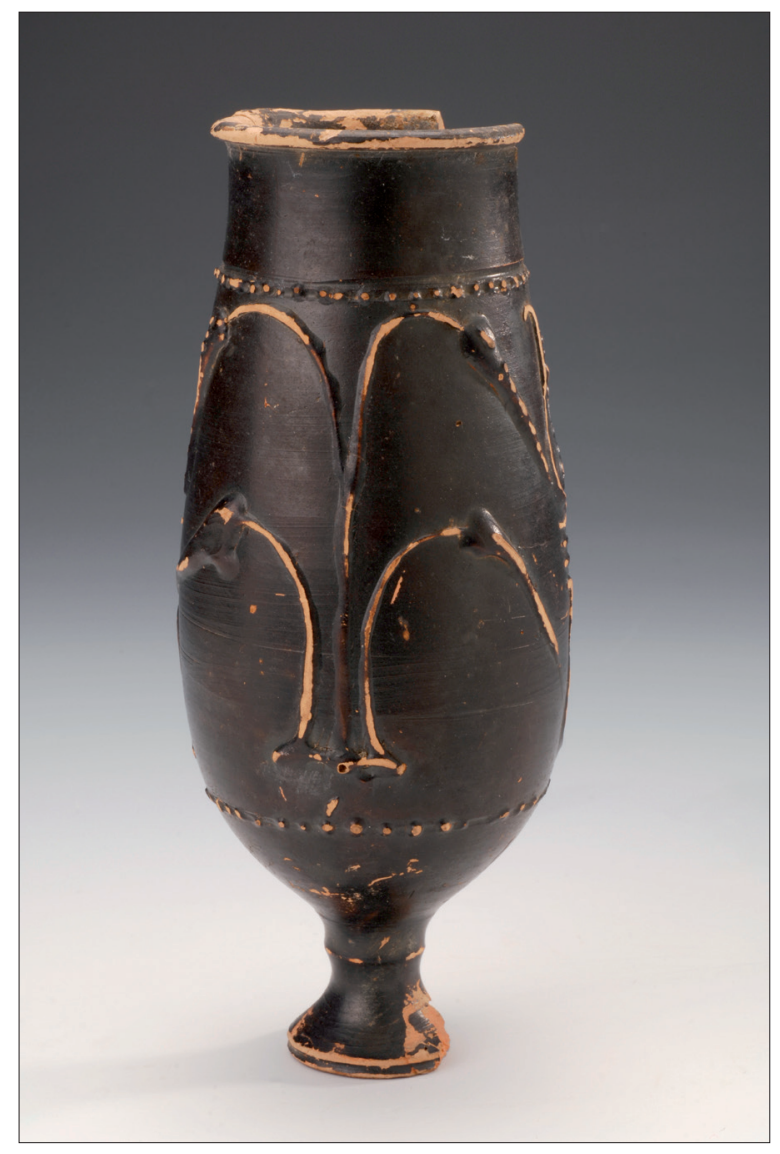

Fig. 5.1. Lezoux 'Rhenish' ware (form Bet 312) with barbotine decoration beneath slip. Musée archéologique de Namur, Collections de la Société archéologique de Namur, $N^{\circ}$ Inv. A08896. Photo L. Baty C SPW archéo (with permission).

\section{I. 2 TECHNOLOGICAL CHOICES}

There is a striking similarity in production practices between sigillata and 'Rhenish' wares. The use of the same types of calcareous clays ${ }^{540}$ stands out as meaningful given the importance of the switch from non-calcareous to calcareous clays for sigillata production at Lezoux. ${ }^{541}$ The use of strictly calcareous clays was what differentiated sigillata production from other production sequences. Moreover the high aluminium contents of the clays resulted in a red fabric for 'Rhenish' wares akin to that of sigillata. ${ }^{542}$ One could object that the use of the same clays was the result of a simple cost-benefit analysis: if the same workshops produced both products, why bother to arrange access to and transport from different clay beds? However, the respective ranges of $\mathrm{CaO}$ content suggest that there was more at play than a mere consideration of efficiency: that of 'Rhenish' wares was consistently more variable than that of 2 nd century sigillata (but less variable than that of later sigillata). ${ }^{543}$ This means that somewhere along the production process - possibly during preparation of the clay - a distinction was made, resulting in practical (clays for these different products have to be prepared differently) and conceptual (these are not the same products) distance between the two sequences.

In practices of stamping too, initial similarity between production of sigillata and 'Rhenish' wares was followed by divergence. To date only a single epigraphic signature has been attested on Lezoux 'Rhenish' wares: a small intra-decorative retrograde stamp reading LVCIM, unknown elsewhere. ${ }^{544}$ Anepigraphic stamps consisting of concentric circles are slightly more common and possibly relate to a metalworking feature. ${ }^{545}$ Whereas the very practice of stamping recalls sigillata, 'Rhenish' ware stamping was rare, anepigraphic, and lacks consistency as to types of stamp used or types of vessel stamped.

The use of barbotine trails underneath the slip was the most frequent among a range of different techniques employed in the decoration of 'Rhenish' wares (Fig. 5.1). ${ }^{546}$ Barbotine trailing required the clay to be in a more viscous state than was needed for slip. ${ }^{577}$ The materiality of this process not only necessitated a specific skill - distinct from sigillata mould making - but also set limits to the amount of detail and precision possible. As a consequence, while the contemporary decorative canons for moulded sigillata were characterized by plasticity and variety of figure-types, 'Rhenish' ware decoration was restricted to

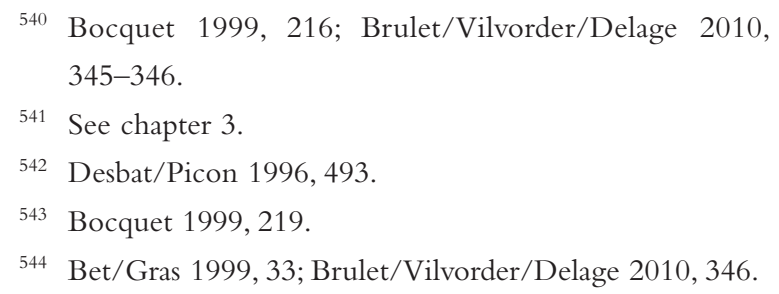
545 Bet/Gras 1999, 26, 33. Also attested at Jaulges-Vil- liers-Vineux (Séguier/Morize 1996, 158).
546 Bet/Gras 1999, 33-34; Brulet/Vilvorder/Delage 2010, 346-347; Symonds 1992, 17-26.
547 Symonds 1992, 13.


vegetal friezes (although figurative hunting scenes were being produced too). As such 'Rhenish' wares were differentiated from sigillata, both in terms of the practical skill required in their production process and in the possibilities of the end product.

But 'difference' is not the end of the story. Among the less frequently used decorative techniques were applied (e.g. for mortaria Drag. 45), incised ${ }^{548}$, and moulded decoration. The latter highlights the relation with decorated sigillata, which was consistently realized using moulds. At Jaulges-Villiers-Vineux (Mid Gaul) moulding on 'Rhenish' wares was employed only for the Drag. 37 bowl, a central form in the sigillata repertoire. ${ }^{549}$ In this case, form and decorative technique were thus borrowed as a package from the sigillata 'category'. Nevertheless 'Rhenish' ware moulds were again differentiated from sigillata by a more limited decorative approach and lack of signature. ${ }^{550}$

The crucial aspect distinguishing 'Rhenish' wares from sigillata was their mode A firing ${ }^{551}$, in a reducing atmosphere, followed by an oxidizing cooling phase. Practically, this meant that sigillata and 'Rhenish' wares could not conceivably have been fired in a single kiln load. Moreover, chemical analysis has shown that the slips applied to 'Rhenish' wares were of a different composition than those in contemporary use for sigillata. ${ }^{52}$

Visually, the different firing mode and slip resulted in a black colour for 'Rhenish' wares, in stark contrast to the bright red of sigillata (Fig. 5.1). Chapter 3 discussed the experimentation with black sigillata before sigillata had become a 'category'. But this return to a black surface colour after sigillata production had crystallized as a bounded 'category' was more than an instance of experimentation. Because sigillata's surface colour was now standardized as red, the black surface colour of 'Rhenish' wares was first and foremost marked out as 'not red', and thus 'not sigillata'. Put differently, 'Rhenish' wares' black surface worked as a boundary marker for the category of sigillata. What would at first glance appear to be the same instance of artefact variability ${ }^{533}$ (how black stands to red) thus has very different leverage depending on the products' historical trajectories: black and red as experimental differences, or black versus red as categorical opposites. This is yet another example of how a non-retrospective approach to material culture allows for better history-writing.

This choice of black was directional: the black colour of 'Rhenish' wares should be interpreted in relation to the red colour of the 'category' of sigillata. This is rendered even more explicit by attestation of some forms exclusive to 'Rhenish' wares (Bet 310) but with a red exterior colour, which have also been found at consumption sites (e.g. Clermont-Ferrand). ${ }^{554}$ By using the sigillata surface colour (red), these 'Rhenish' ware forms established a reference to the category of sigillata. In contrast to these references outwards from 'Rhenish' wares, the production sequence of sigillata remained entirely self-referential.

As to the form repertoire it is generally held that 'Rhenish' wares comprise drinking vessels, in contrast to the dining and serving vessels produced in sigillata. ${ }^{555}$ As such 'Rhenish' wares are seen as heir to a longer tradition of 'Italian style' drinking services, ranging from thin-walled beakers to colour-coated wares. ${ }^{556}$ Symonds even hints at a system of colour coding for Roman pottery from the 1st century AD onwards which reserved red for serving and dining, and black or dark colours for drinking. ${ }^{557}$

But in the case of Lezoux, the contrast between sigillata or 'Rhenish' ware forms is not that stark. 'Rhenish' wares undeniably tapped into the established drinking repertoire previously associated with colour-coated wares, but also took on some forms derived from the by now standardized sigillata rep-

\footnotetext{
548 Cf. glass production (Greene 2007).

549 Séguier/Morize 1996, 165.

550 Brulet/Vilvorder/Delage 2010, 346.

551 Picon 1973; Bocquet 1999, 223-225.

552 Bocquet 1999, 223.

553 Cf. Hodder/Hutson 2003, 173 ff.
}

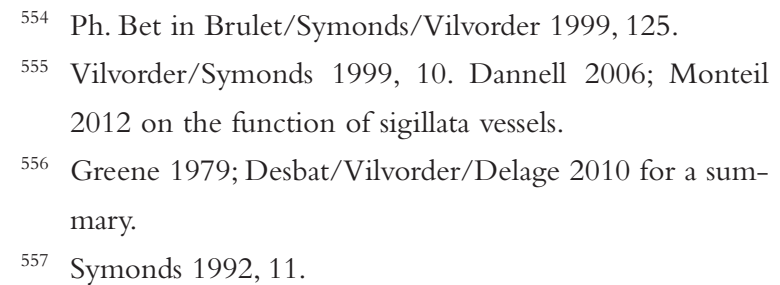

$554 \mathrm{Ph}$. Bet in Brulet/Symonds/Vilvorder 1999, 125. 2012 on the function of sigillata vessels.

Symonds 1992, 11. 


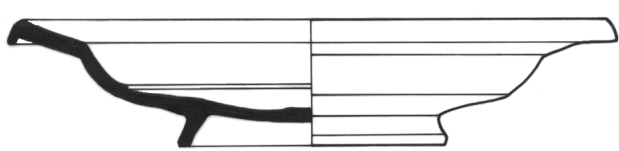

Bet 301

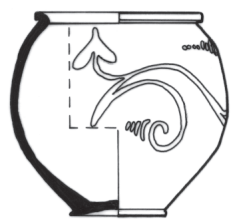

Bet 305

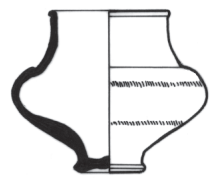

Bet 308

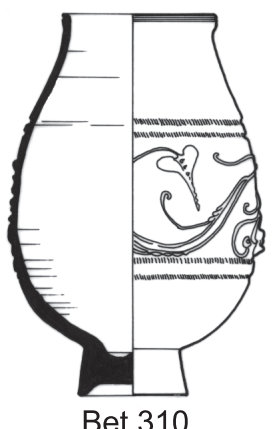

Bet 310

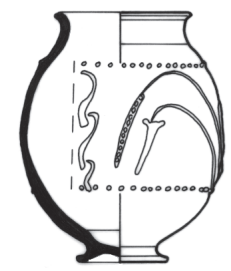

Bet 306

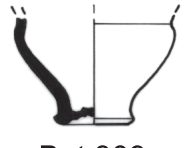

Bet 309

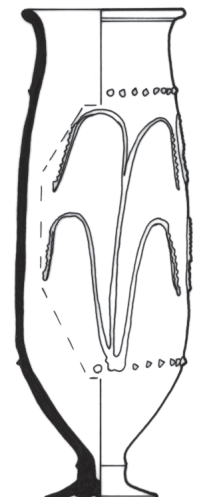

Bet 312

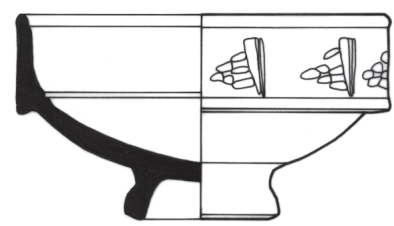

Bet 316

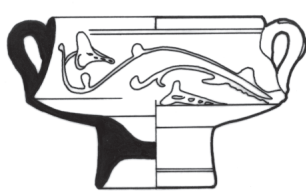

Bet 302

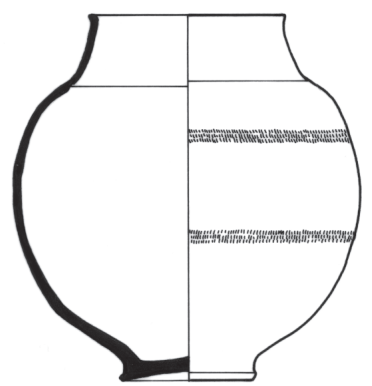

Bet 307

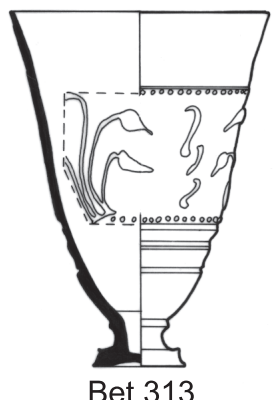

Bet 313

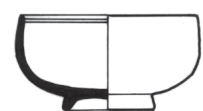

Bet 303

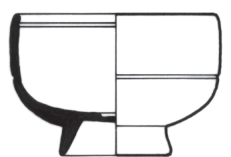

Bet 304

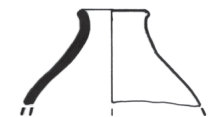

Bet 311

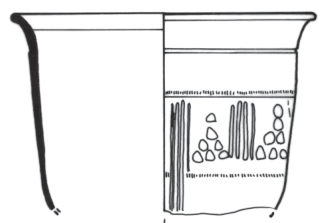

Bet 314

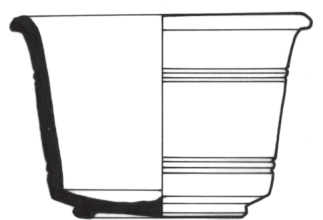

Bet 315

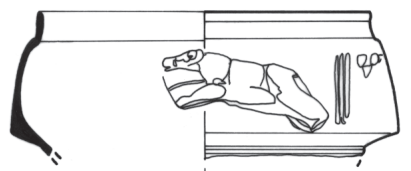

Bet 317

Fig. 5.2. Typology Lezoux 'Rhenish' wares (second half 2nd century AD). (C) Centre de Recherches d'Archéologie Nationale, UCL. From Brulet/Vilvorder/Delage 2010, 347 (with permission).

ertoire, such as Drag. 40 (Bet 304) and Drag. 45 (Bet 316) (Fig. 5.2). ${ }^{558}$ Desbat and Vilvorder emphasize this partial convergence with sigillata forms. ${ }^{599}$ In contrast to the preceding colour-coated wares, ${ }^{\text {Rhen- }}$ ish' ware forms thus enacted a more complex dialogue of similarity and difference in relation to sigillata. Moreover, the choice of sigillata forms adopted in the 'Rhenish' ware production sequence varied across production sites. ${ }^{560}$ It follows that no standard set of 'Rhenish' ware forms existed across Gaulish production sites at that period, but that it was the relation with sigillata that was maintained and explicitly (re-)negotiated.

558 Bet/Gras 1999, 26-31; Brulet/Vilvorder/Delage 2010, 346-347.

559 Desbat/Vilvorder 2000, 178.

560 Bet/Gras 1999, 26. The 'Rhenish' ware repertoire at Jaulges-Villiers-Vineux (late 2nd-early 4th century) included Drag. 37, in contrast to Lezoux 'Rhenish' wares, but no sigillata production has been attested at the site (Jacob/Leredde 1985, 1994; Joly 1999, 57-61; Séguier/ Morize 1996). 
Finally, where does this leave the definition of 'Rhenish' wares? One recurring feature is the latitude of variation in the respective technological choices, from the variable range of $\mathrm{CaO}$ contents to the different decorative techniques used. But these variable properties were united by their clear differentiation from sigillata practices. For example, the colour of 'Rhenish' wares could take on aspects of dark black, red, brown, or green ${ }^{561}$ - but all of these shades stood in a relation of marked difference to the standardized red of sigillata. Therefore they served to delineate the external boundaries of the 'category' of sigillata - what was not sigillata - rather than positively defining a 'category' of'Rhenish' wares. A similar observation can be made concerning sintering: 'Rhenish' wares were more or less sintered, like sigillata ${ }^{562}$, but, in contrast to sigillata, never achieved the same shiny aspect. Hence latitude in a single technological choice did not preclude consistency in the external relation of difference to another product.

\section{I . 3 B OUNDARIES AN D 'OTHERING'}

Discussion of the technological choices of 'Rhenish' ware production at Lezoux has demonstrated that these existed in a complex relation of similarity and difference to sigillata, that they enacted a marked one-way reference, and that this reference prevailed on any positive definition of 'Rhenish' ware itself. In other words, 'Rhenish' wares were defined by their relation of 'Otherness' to sigillata. This explains the impossibility of scholarship's attempt at pinning down a limited set of parameters for the identification of 'Rhenish' wares - in contrast to terra sigillata.

Producing 'Rhenish' wares thus always also amounted to defining what sigillata was not. This illustrates the 'boundary work' needed to reaffirm the external boundaries of sigillata and to maintain its definition as a 'category'. ${ }^{563}$ Indeed, a 'category' can attain a relative degree of stability, but this requires continuous effort. ${ }^{564}$ One could for example trace the career of the computer from a technological oddity with limited stakeholders to a bounded 'category' whose relational entanglement is as wide-ranging as it is obscure. On the one hand, the extent and regularity of the computer's embeddedness in various fields of practice (e.g. education, administration, etc.), and the attendant adjustment of standards, render a sudden and dramatic reordering unlikely. On the other hand, the boundary between the computer and a wide range of other things is constantly challenged in practice: think about mobile phones with internet access and a keyboard instead of a number pad; notebooks; tablets; Skype; etc. If boundaries are to be maintained, practical work is to be done.

The boundary work for Lezoux sigillata was done through the production practices for 'Rhenish' wares. On the one hand, initial similarity in practices was necessary to indicate a directional reference to sigillata: they were produced in the same workshops, used the same clays, had some overlapping forms, could carry stamps, etc. On the other hand, marked difference in the implementation of the technological choices created a perception of difference in relation to sigillata: 'Rhenish' wares were black instead of red, tended to be decorated with barbotine instead of moulding, mostly comprised drinking forms instead of dining and serving vessels, carried anepigraphic stamps (if any) instead of epigraphic ones, had no strict rules for clay preparation in contrast to sigillata, etc. As a consequence, sigillata was re-affirmed as a homogeneous and bounded 'category' through repeated characterisation of the practices associated with 'Rhenish' wares as 'Other': as separate, but mutually implicated. This process was not concerned with freezing the actual contents of the sigillata 'category', but with preserving its definition as a 'category' by keeping its boundary active and well-defined.

561 Symonds 1992, 18; Brulet/Vilvorder/Delage 2010, 346

562 Brulet/Symonds/Vilvorder 1999, 10.

563 Cf. Mol/Law 2005.
564 STS opinions on this diverge: Law 2004, 56 ff., 2010; Callon 1991. 


\subsection{RO O T E D THINGS: FRO M L E Z O U X T O TRIER}

\subsection{S I T U A T I N G T R I E R}

To analyse how the stabilized 'category' of sigillata was transmitted to other production sites, we move northwards to Trier in East Gaul (Fig. 3.2) ${ }^{565}$ Augusta Treverorum was founded during the last quarter of the 1st century BC on the site of a Roman army camp in the territory of the Treveri, one of the most significant tribes in Gaul. ${ }^{566}$ Its foundation and history are testimony to political, military and commercial voluntarism: the city was built from scratch on a strategic location along the river Mosel, in between the previous strongholds of the Treveri (Titelberg and Martberg). ${ }^{567}$ Moreover, in 19/18 BC Agrippa established a privileged road link from the Mediterranean via Lyon to Trier and the military outposts along the Rhine. ${ }^{568}$

Hence it should cause no surprise to see Trier develop into the political and economic heart of the northern Roman empire. The presence of Italian merchants has been attested from early in the 1st century AD onwards, monumental building programmes took off during the 2 nd century ${ }^{569}$ and continued into the first part of the 3rd century as Trier thrived through the input of landowners trading their products. Politically Trier entered a different type of organisation in the 3rd century, as it became capital of the Gaulish part of the later empire, taking over from Cologne in AD 270. Raids and invasions by the Germani abruptly put an end to this prominence in AD 275, but eventually Trier regained its position as the capital of the Western empire under Maximian from AD 286 onwards.

The oldest evidence of pottery activity at Trier - one among many crafts ${ }^{570}$ - dates to the Augustan period: five kilns containing misfired ceramics were discovered in the northwest area of the ancient town, and another kiln was found in the northern area. Both were short-lived ${ }^{571}$ and from the middle of the 1 st century AD onwards, a large area $(400 \times 200 \mathrm{~m})$ south of the city was devoted to pottery activity. Here sigillata production has been identified around AD 130, followed by 'Rhenish' wares around the turn of the 2 nd century. ${ }^{572}$ Soon after their introduction, 'Rhenish' wares outnumbered sigillata in quantity and quality at Trier. Political or economic hypotheses for the demise of the Central Gaulish sigillata export and the flourishing of the East Gaulish centres remain hard to substantiate. ${ }^{573}$ Did the definition of sigillata as a 'category' change between Lezoux and Trier? How did this alter the possibilities of its 'Other', 'Rhenish' wares?

Before we proceed to investigate these questions, some chronological difficulties need introduction. Künzl has established a chronology of Trier 'Rhenish' wares on the basis of decorative elements, the dating of which is linked to a number of closed contexts. ${ }^{574}$ However the lack of appropriate assemblages and comparanda renders any attempt at dating between the end of the 2nd and the beginning of the 3rd century AD highly contentious. This study will claim a link between the changes in Trier sigillata production and the introduction of 'Rhenish' wares at the end of the 2nd century AD. The suggested date is of less importance to the argument, since the emphasis is on relative changes. But Künzl's first group

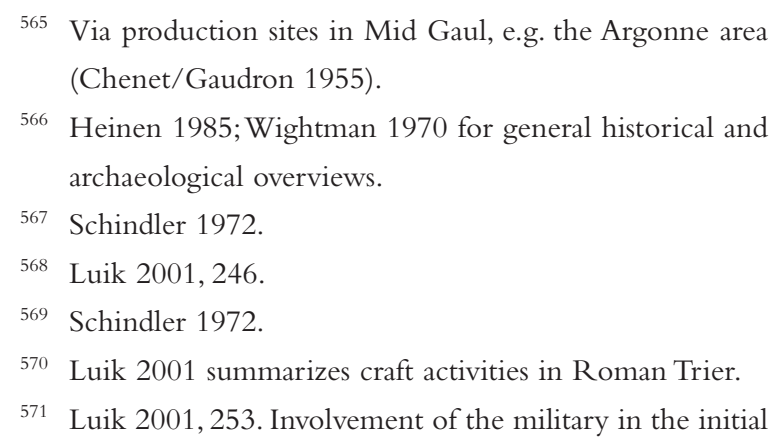

566 Heinen 1985; Wightman 1970 for general historical and archaeological overviews.

567 Schindler 1972.

568 Luik 2001, 246.

569 Schindler 1972.

570 Luik 2001 summarizes craft activities in Roman Trier.

571 Luik 2001, 253. Involvement of the military in the initial

transmission of crafts is likely but not supported empirically.

572 Brulet/Vilvorder/Delage 2010, 191 ff., 351 ff. Earlier 'Rhenish' ware production is attested in Mid Gaul, e.g. at Jaulges-Villiers-Vineux.

573 E.g. Symonds 1992, 46 on the usurpation by Clodius Albinus and subsequent punitive measures by Septimius Severus.

574 Künzl 1997. 
of decorated 'Rhenish' ware does not start until AD 255. This makes it difficult to weave her insights on decorative choices into the analyses of the other technological choices discussed below.

The dating of Künzl's first group of decorated Trier beakers is based on an overlap in form with plain 'Rhenish' wares, the chronology of which is in turn anchored by their occurrence on the limes forts. ${ }^{575}$ But King's work on the chronology of the 3rd century in the northwestern provinces has demonstrated that the concept of a dated site is a very fragile construct that at the very least needs support from closed deposits, preferably yielding associations with coin evidence. ${ }^{576}$ Moreover, it is generally held that barbotine, by far the commonest decorative technique on Trier 'Rhenish' wares, was introduced from Rheinzabern. Whereas the mechanisms of this process of craft interaction are unclear and should at the very least be contextualized, Künzl equates the start of decorated 'Rhenish' ware production at Trier with this supposed incursion of Rheinzabern potters: 'So wird die Gruppe I wohl unter dem persönlichen Einfluß oder durch die Hand eines oder mehrerer Rheinzaberner Töpfer entstanden sein'. ${ }^{577}$ This supposedly took place at a time when Rheinzabern was faced with a declining export reach due to military developments. Because the chronology of the industry at Rheinzabern itself, however, does not stand firm, this event has been variously dated to around AD $233^{578}$ or to the period between AD 255 and $260^{579}$. It is not until the third group that Künzl's dates are confirmed by closed context assemblages.

\section{2 .2 W O R K S H O P S}

In the southern production area at Trier more than 100 kilns and a number of other structures have been unearthed but remain largely unpublished. ${ }^{580}$ Production of so-called 'Belgic' and colour-coated wares (from the beginning of the 2nd century onwards) preceded the introduction of sigillata, which is dated to AD $130 .^{581}$ Given the indirectly continued dialogue between colour-coated wares and 'Rhenish' wares at Lezoux discussed above, it is significant that the start of sigillata production at Trier follows in the wake of colour-coated wares. ${ }^{582}$ As such something of a package of tablewares took off, catering for both dining and drinking needs. Around the end of the 2nd or the beginning of the 3rd century 'Rhenish' ware production was introduced in the same southern production area, shortly after its development at Lezoux. ${ }^{583}$

What distinguishes Trier as a ceramic production centre from previous major rural pottery hubs such as Lezoux and La Graufesenque is its integration in the urban fabric. ${ }^{54}$ Consequently it seems a reasonable assumption that the potters would have had more direct knowledge of and involvement with the activities and needs of their investors and consumers (merchants, town residents and the military). Moreover, the southern production area consisted of a continuous strip including workshops and domestic structures, a layout more conducive to intra-craft encounters than the spatially distinct groups at Lezoux. This daily experience of place must have contributed to the creation of a community of practice, establishing the social ties crucial to partnerships and economic formations. ${ }^{585}$

This sense of place was challenged when the city wall was erected around AD 180, dividing the pottery area in an intra muros (Louis-Lintzstraße) and extra muros (Pacelli-Ufer ${ }^{586}$ ) part. ${ }^{587}$ The observation

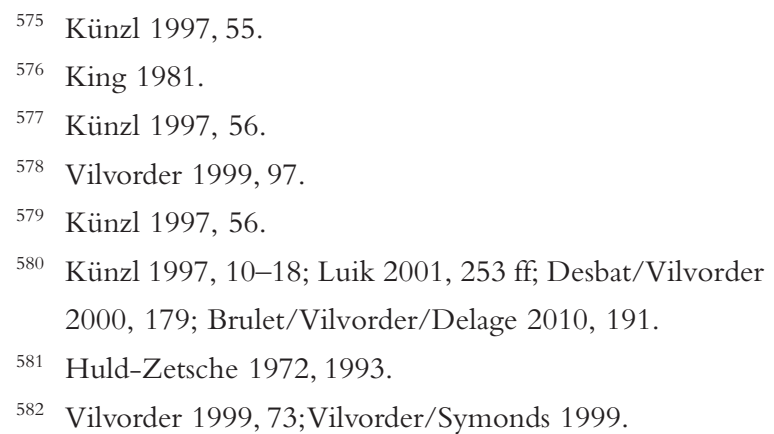

582 Vilvorder 1999, 73;Vilvorder/Symonds 1999.

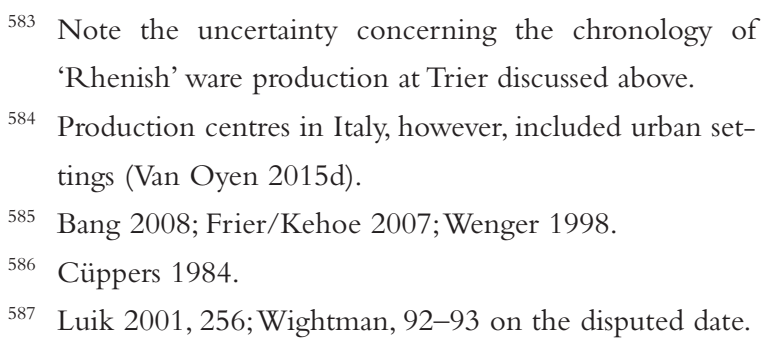


that the wall disturbed previous kilns ${ }^{58}$ hints at a top-down reorganisation. This new physical boundary would have initiated a changed experience of daily life and communication. These interventions were contemporary with, or slightly preceded, the introduction of 'Rhenish' ware production, but the chronology is too uncertain ${ }^{589}$ and the published structural evidence too fragmentary ${ }^{590}$ to link both observations (e.g. was the production of 'Rhenish' wares preferentially associated with one of the two areas created by the wall?). As far as can be judged from the mixed finds assemblages and the seemingly random disposition of very different types of kilns across the entire production area, it is unlikely that any specialisation formed through spatial segregation. ${ }^{591}$ Attempts to link specific kilns to specific ceramic products remain contentious. A single kiln on the Pacelli-Ufer (outside the city wall) has been attributed to the production of 'Rhenish' wares. ${ }^{592}$ The kiln has a large firing chamber, a flask-like shape with a central support wall and a series of bulges protruding from the southern wall.

\section{$5 \cdot 2 \cdot 3$ EARLY TRIER SIGILLATA: ON ITS OWN TERMS}

Upon introduction at Trier, sigillata used the same non-calcareous clays as the preceding colour-coated wares $^{593}$ (average $\mathrm{CaO}$ contents $3 \%$ with outliers). ${ }^{594}$ This is in stark contrast to what is presented in sigillata scholarship as the 'sigillata package' or to the 'category' of sigillata as it crystallized some decennia later at Lezoux. For early sigillata at Trier the later maxim 'calcareous clays equal quality' did not hold true. Indeed, products from the first sigillata workshops at Trier (Werkstatt I (AD 130-150/160) and Werkstatt II (AD 140/145-165/170) ${ }^{595}$ ) are generally characterised by fine, homogeneous clays, and thick, sintered and shiny slips. ${ }^{596}$ Hence Picon's model, which posits the use of calcareous clays as a universal token of higher investment and hence higher quality, does not work for Trier (or East Gaulish) sigillata production. ${ }^{57}$ Meanwhile the reddish sigillata slips contrasted with the dark grey to black or brownish, non-sintered slips of colour-coated wares. ${ }^{598}$ It follows that early Trier sigillata enacted relations and parameters of its own, not in response to 'sigillata' as defined elsewhere.

The forms of this initial sigillata production have only been charted for stamped plain wares and decorated wares. Both series corresponded to the sigillata repertoire fashionable in contemporary production centres. ${ }^{599}$ But in addition a limited number of shapes, possibly derived from Mid-Gaulish examples, suggests experimentation with forms that were not exported. ${ }^{600}$ This gives yet another clue that initial Trier sigillata production was not defined as a 'category' in tune with Lezoux.

Huld-Zetsche has catalogued the decorative schemes and figure-types used during the early sigillata production at Trier. ${ }^{601}$ The themes run parallel to those favoured at Lezoux: gladiatorial combat, hunting scenes, or erotic scenes. Initially little care was given to the decoration, and broken figure stamps for example were often reused. ${ }^{602}$ This observation is again difficult to marry with the template of the 'category' of Lezoux sigillata. But because this was not how early Trier sigillata was defined and evaluated,

588 Cüppers 1973, 150.

589 Brulet/Vilvorder/Delage 2010, 355.

590 Künzl 1997 summarizes the excavation campaigns.

591 Huld-Zetsche 1972, 16.

592 Künzl 1997, 17.

593 Bocquet 1999.

594 Analyses by Picon in Huld-Zetsche 1978, 328-334, esp. nrs. 1-15. Werkstatt II had some outliers with a $\mathrm{CaO}$ content of 6 à 7 \% (Huld-Zetsche 1978, 333 nrs 16-29; Brulet/Vilvorder/Delage 2010, 191, 193-194).

595 Huld-Zetsche 1972, 1993 for decorated sigillata. Little research has been done on plain Trier sigillata, except for a single unpublished study on stamps.

596 Brulet/Vilvorder/Delage 2010, 193.

597 Picon 2002a.

598 Brulet/Vilvorder/Delage 2010, 329.

599 Brulet/Vilvorder/Delage 2010, 194; Huld-Zetsche 1972, 48-50, 1993.

600 Huld-Zetsche 1972, 49.

601 Huld-Zetsche 1972, 1993.

602 Huld-Zetsche 1972, 22. 
'careless' decoration did not by definition stand in opposition to high quality slips and well-fired fabrics. Put differently, these were not mutually implied elements of a package of traits, whereby presence of one of these traits would imply presence of the entire package.

\section{2 .4 TRANSPOSITION OF A 'C ATEGORY' AND ITS 'OtheR'}

Previous chapters discussed how sigillata became a 'category' at Lezoux around the middle of the 2nd century, closely followed by the introduction of 'Rhenish' wares. Through relations of similarity and difference, the technological choices of 'Rhenish' ware production helped maintain the homogeneity and boundedness of the sigillata package, including the use of calcareous clays and oxidizing firing. Despite the crude chronology it is significant that the same major changes took place in the pottery landscape at Trier around the second half of the 2 nd century: 'Rhenish' wares using calcareous clays ${ }^{603}$ were introduced and sigillata production shifted to calcareous clays ${ }^{604}$. Trier sigillata of the second half of the 2nd century closely resembles contemporary Lezoux products, including matt and less adherent slips and a Central Gaulish form repertoire. Moreover, it was not until the later part of the 2nd century that the practice of signing sigillata moulds was taken up at Trier as in other sigillata centres. It is thus possible to suggest that sigillata production was transposed as a well-defined package of traits (a category) from Central Gaul to Trier. This would have been facilitated by the joint transposition of the category's boundary marker: the relation of its production practices to 'Rhenish' ware production.

The 'who' and 'why' questions concerning this technological shift remain obscure. One possible piece of the jigsaw might be the gradual move of potters associated with Werkstatt I to Sinzig, deduced on the basis of a striking overlap between figure types and identical figure stamps. ${ }^{605}$ In any case a subsequent active process of negotiation between different ways of doing is suggested for Trier by sherds attributed to the same 'style' (e.g. Comitialis) but using either calcareous or non-calcareous clays. ${ }^{606}$ Unfortunately detail is insufficient to reconstruct the specificities as Chapter 3 did for Lezoux.

Nevertheless, evidence suggests that 'Rhenish' wares at Trier did indeed initially stand in a relation of 'Otherness' to the newly introduced sigillata production 'à la Lezoux'. As in the case of Lezoux where the $\mathrm{CaO}$ contents of 'Rhenish' wares was more varied than that of contemporary sigillata, the use of similar clays for 'Rhenish' wares and sigillata at Trier did not entail a complete overlap of their production sequences. Whereas the $\mathrm{CaO}$ contents of sigillata in the second half of the 2 nd century averaged $7 \%$, that of 'Rhenish' wares of the same period barely reached a level of $4,44 \% \mathrm{CaO} .{ }^{607}$

With regard to slips and firing mode too a subtle balance between similarity (sintered slips) and difference (black/dark colour, mode A firing versus red colour, mode C firing) ${ }^{608}$ was enacted both in practice and in the resulting end products. Furthermore, it is likely that barbotine trailing - which later became the main decorative technique for Trier 'Rhenish' wares - was perceived as being part of the transmitted package of the 'category' sigillata and its 'Other' 'Rhenish' wares - even though this does not exclude other empirically traceable origins (e.g. Rheinzabern ${ }^{609}$ ). This interpretation is supported by the observation that the earliest 'mottoes' - short Latin inscriptions painted on 'Rhenish' ware vessels - were applied using a dotted barbotine technique already occasionally used in Central Gaul for both sigillata

\footnotetext{
603 Vilvorder 1999, 77; Bocquet 1999, 182.

604 Analyses by Picon in Huld-Zetsche 1978, 334 nrs 41-54; Schneider 1993.

605 Huld-Zetsche 1972, 25-27; Hartley 1977.

606 Brulet/Vilvorder/Delage 2010, 195.

607 Trier C group: Brulet/Vilvorder/Delage 2010, 195, 353;
}

Bocquet 1999, 167.

608 Bocquet 1999, 182-183.

609 Künzl (1997, 119-120) emphasizes the Rheinzabern origins of this technique, but does not discuss how it was appropriated at Trier. 


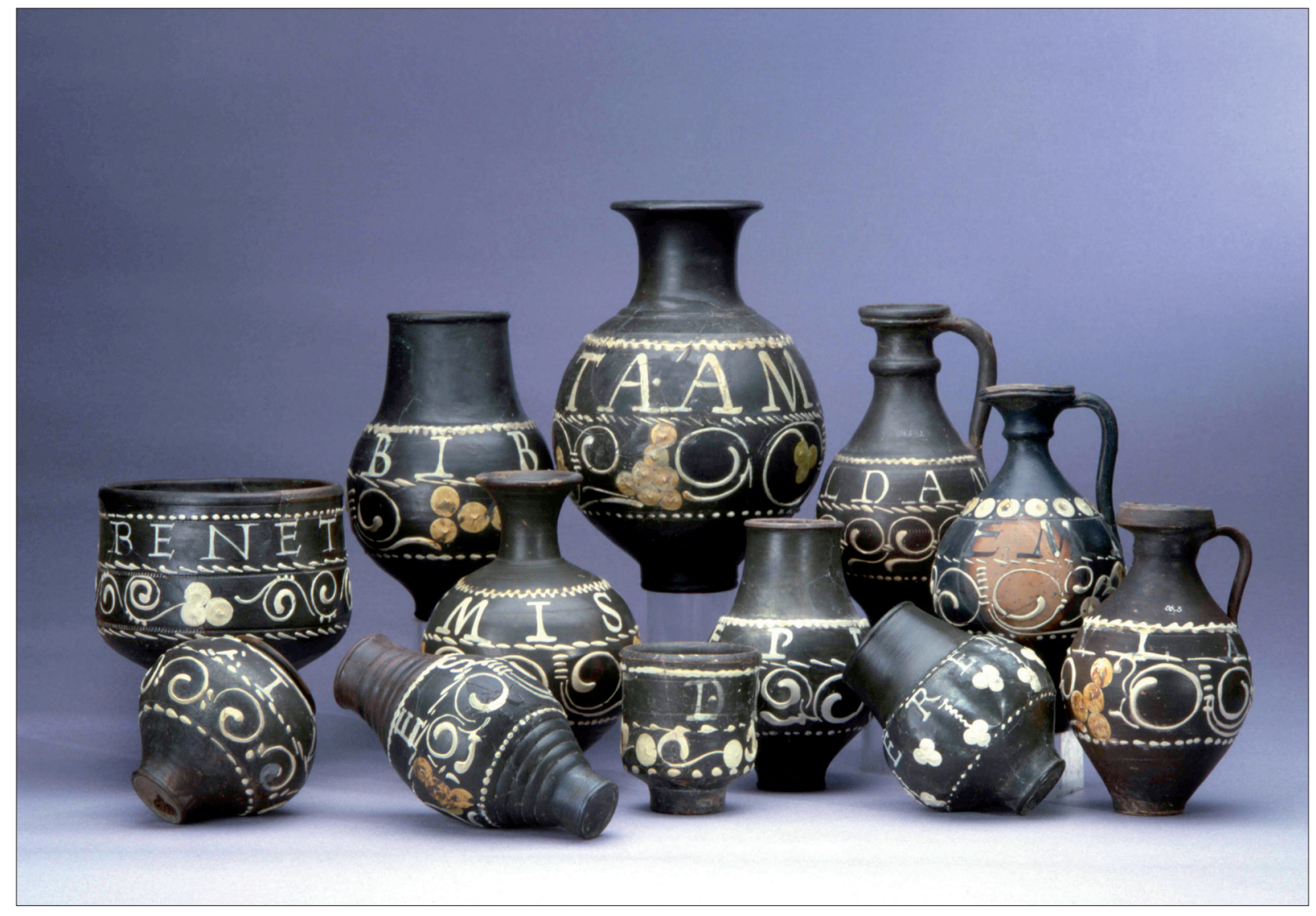

Fig. 5.3. Trier 'Rhenish' wares with painted mottoes in barbotine. (C) Rheinisches Landesmuseum Trier (with permission).

and 'Rhenish' wares ${ }^{610}$ Finally, in practical terms white pipe-clay had to be imported to produce barbotine $^{611}$, instigating a further difference with the production sequence of contemporary sigillata.

5.2 .5 THIRD CENTURY SIGILLATA： A 'CATEGORY' DISSOLVED

By the early 3rd century this dotted technique was replaced by painted mottoes on 'Rhenish' wares (Fig. 5.3), which thus escaped their defining relation with the template of sigillata as a category imported from Central Gaul. How could this happen? There are indications that contemporary sigilata production was no longer maintained as a 'category' at Trier, but that its either/or boundaries dissolved and its package of traits was obliterated.

During the 3rd century, sigillata slips became rough, adhered badly, and showed considerable latitude of variation in the range of colours (bright red to dark red or even brownish hues) and in their aspect (matt to shiny). ${ }^{612}$ As to decoration ${ }^{613}$, moulds dating back to the initial sigillata production of the 2 nd century AD were being reused, as attested for the so-called Massenfund on the Pacelli-Ufer. ${ }^{614}$ This implies at the very least that the making of new sigillata moulds was not a primary objective of the potters at Trier, and that the category's package of traits was being loosened.

${ }^{610}$ Künzl 1997, 99 (Group I only).

611 Künzl 1997, 92.

${ }^{612}$ Brulet/Vilvorder/Delage 2010, 196.
613 There is a lack of studies on Trier sigillata decoration after Fölzer 1913.

614 Huld-Zetsche 1972, 81-88, 1978. 
This is also demonstrated by a series of new sigillata forms establishing an idiosyncratic repertoire for Trier. ${ }^{615}$ The influences on this repertoire are likely to have come from Rheinzabern, which was the only large sigillata production centre active in East Gaul after AD 200/210. ${ }^{616}$ But just as I argued for the introduction of the barbotine technique, these 'origins' might not have determined how the resulting product was perceived and defined. Instead, what was emphasized by the creation of a formal repertoire at Trier itself seems to have been the 'localness' of ceramic production, in contrast to the 'global' currency of the previous sigillata 'category'.

\subsubsection{THIRD CENTURY 'RHENISH' WARES: VARYING TECHNOLOGICAL C H O I C E S}

As the category of sigillata was dissolved, 'Rhenish' ware production gradually escaped the orbit of sigillata. This does not mean that their respective production sequences no longer had any relation, but that, if anything, the directionality of this relation shifted. To illustrate this with a modern parallel: the mobile phone was initially shaped by its recursive relation of similarity and difference to the 'normal' telephone - by what it 'added' to the already known package of 'telephone' - with which it shared most practices while adding the concept of mobility. Despite the continued visual and practical links, however, this relation has receded into the background, or at least shifted its directionality: the original telephone, what it can do, and what it cannot do now need to be discursively defined as a 'mobile phone' but wired and hence stationary. To refer to the mobile phone, on the other hand, no discursive reference back to the practices of the previous telephone is needed anymore. So too 3rd century 'Rhenish' wares were no longer defined 'by implication' based on sigillata's production practices.

A number of technological choices underwrite this reversed relation and show how 'Rhenish' ware production now played with occasional but not-defining references to sigillata. For example a number of examples with a red exterior similar to sigillata have been attested in Künzl's Group IV of decorated 'Rhenish' wares (AD 280-310/315) ${ }^{617}$ These can be distinguished from the occasional sigillata with barbotine decoration since the former's red colour was the result of reoxidation of non-sintered surfaces after reducing firing (mode A). Hence the surface of the end product was less smooth than that of sigillata fired in an oxidizing atmosphere, according to mode C. Another example concerns the crater Thomas 6, originally a sigillata form at Rheinzabern ${ }^{618}$, but appropriated and rendered popular as a typical 'Trier' 'Rhenish' ware vessel. Finally, at Trier itself examples of Drag. 45 technically belonging to the sigillata production sequence have been noted with decoration indicative of 'Rhenish' wares. ${ }^{619}$

Alongside this shifting directionality, 'Rhenish' ware production now developed relations to production sequences other than sigillata too. Meanwhile - and in contrast to the earlier category of sigillata - a lot of variation was tolerated within the technological choices of 'Rhenish' ware itself. For example, while the two identified groups of 'Rhenish' ware fabrics are related by their use of 'slightly' calcareous clays (Trier B 2,43\% CaO; Trier C 4,44\% CaO), the overall chemical composition of the Trier B 'Rhenish' ware fabrics is much more similar to that of the colour-coated fabric Trier A. ${ }^{620}$ While this might be in part a matter-of-fact result of the great diversity of geology and clay sources surrounding Trier ${ }^{621}$, it goes to show the consistent space for variation allowed for in 'Rhenish' ware production.

\footnotetext{
615 Brulet/Vilvorder/Delage 2010, 196.

616 Vilvorder 1999, 75.

617 Künzl 1997, 92.

618 Brulet/Vilvorder/Delage 2010, 196.
}

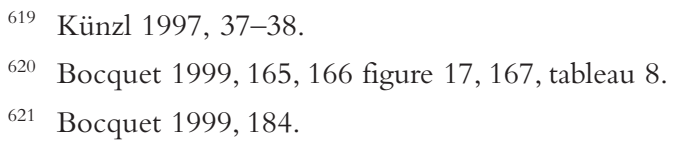

21 Bocquet 1999, 184. 

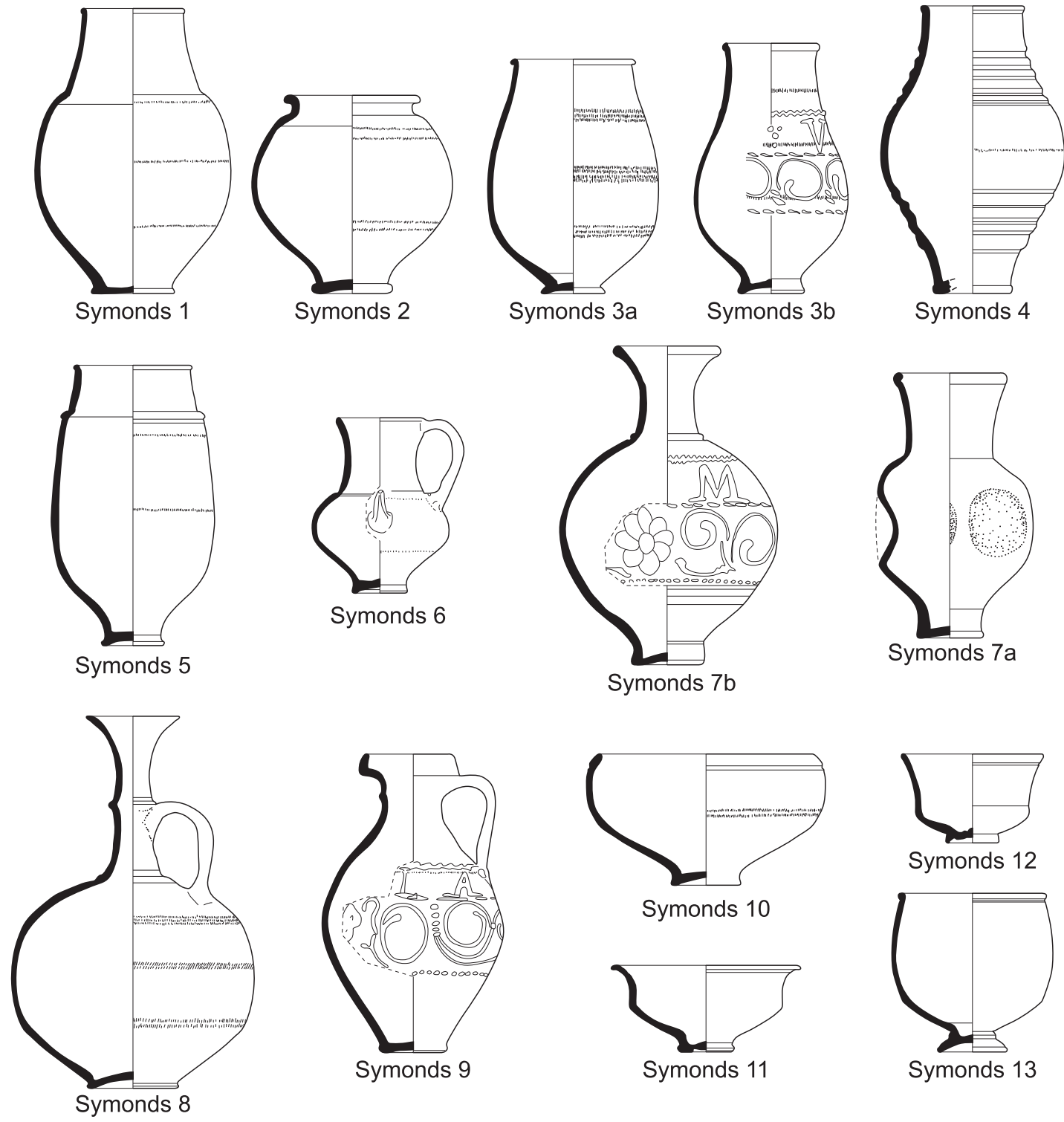

Symonds 12
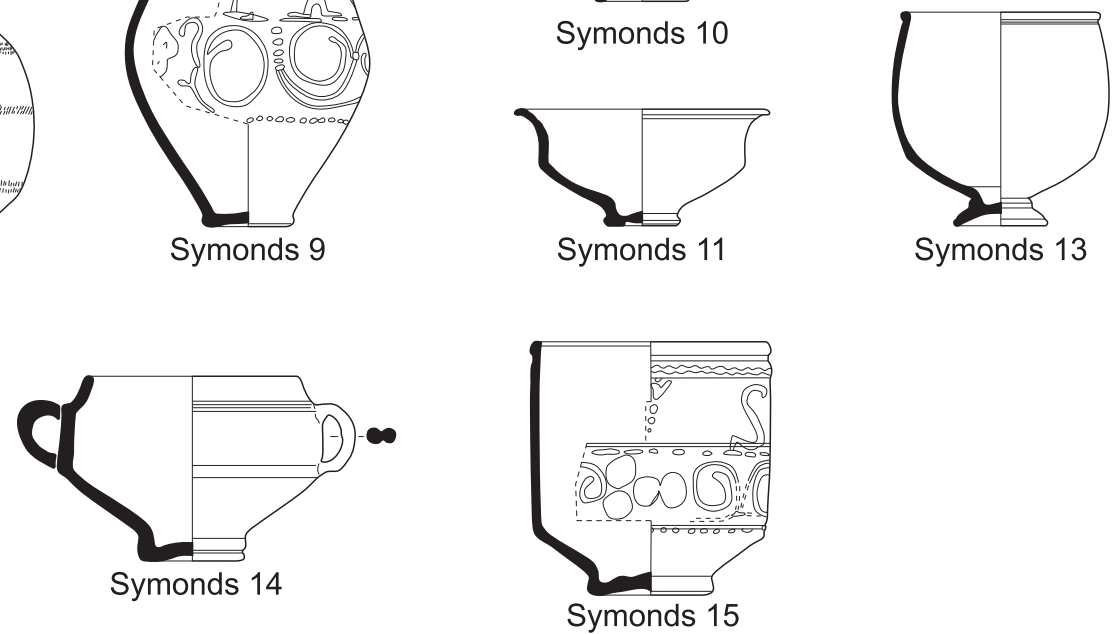

Fig. 5.4. Typology Trier 'Rhenish' wares. (C) Centre de Recherches d'Archéologie Nationale, UCL. From Brulet/Vilvorder/ Delage, 354 (with permission).

And again in contrast to the category of sigillata, where vessels within a single 'type' tended to be identical to the extent that weights and dimensions were precisely matched from one vessel to another, standardisation of the formal repertoire of 'Rhenish' wares in the 3rd century (Fig. 5.4) did not preclude variation and experimentation. Firstly, variations existed between vessels of the same general form so that 'each vessel is unique' ${ }^{622}$. Secondly, different sizes existed for a single vessel type, from miniature to extra

622 Symonds 1992, 49. 

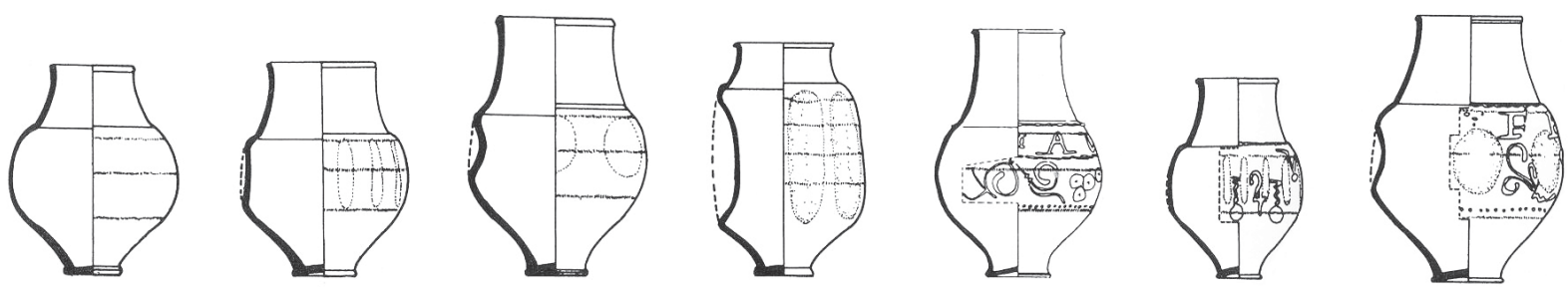

Fig. 5.5. Variations on 'Rhenish' ware type Niederbieber 33. Modified after Vilvorder 1999, 98 Fig. 13.

large; but no strict modules prevailed, as was the case for sigillata. ${ }^{623}$ Fig. 5.5 charts some of the variation in size and shape within the most popular 'Rhenish' ware form, Niederbieber 33. Thirdly, standardisation did not affect all 'Rhenish' wares equally: more variation is evident in the shapes of cups than in any other form. ${ }^{624}$

This leads to functionality, with the standard argument that 'Rhenish' wares were for drinking, while sigillata was for dining. Granted there was a tendency for sigillata and 'Rhenish' wares to preferentially include respectively dining and drinking forms, but this functional differentiation was not as watertight as had been the case at Lezoux. Apart from shared forms (e.g. crater Thomas 6, to be associated with drinking but also embracing cultic functions ${ }^{625}$ ), it is highly contentious to limit the function of the quintessential 'Rhenish' ware cups and bowls to drinking. ${ }^{.26}$ Furthermore, the extreme ends of the scalar continuum of size variation - the miniature and extra large renderings - in all likelihood had an ornamental or symbolic role ${ }^{627}$, transgressing the rigid boundaries of functional classes.

For 'Rhenish' wares 'standardisation' was thus not coterminous with a process of category formation as described for Lezoux sigillata. In his typology of Trier 'Rhenish' wares, Symonds distinguishes between 28 vessel forms produced at Trier. Of these 28 , a single form accounted for over $50 \%$ of the recorded vessels: the type Niederbieber $33^{628}$ (Figs. 5.4 and 5.5), which moreover remained in use for more than 150 years $^{629}$. Whereas this form was already present at Lezoux, there is no reason why it would have been inherently predisposed to becoming the quintessential 'Rhenish' ware form at Trier. So in contrast with the typological standardisation familiar from sigillata, where a series (sometimes even a 'service') of vessel forms was produced in substantial quantities, standardisation in 'Rhenish' wares meant the overt dominance of a single type of beaker.

Similarly, one dominant decorative technique (barbotine) existed against the background of a wide range of other possibilities (painting, appliqué, drawing ${ }^{630}$ ). Künzl explains the infrequent use of the latter options because these techniques would have thwarted a 'rational' (read: least-cost) procedure. ${ }^{631}$ But not only is barbotine itself a highly demanding technique requiring specific preparation and skill, as explained in Chapter 4 it cannot be assumed that a neoclassical notion of 'rationality' as 'cost-benefit analysis' was applied for evaluating the procedures of 'Rhenish' ware production. Instead, this research shows how this pattern resonated with other technological choices to define 'Rhenish' wares in a specific way. As to decorative compositions, non-figurative schemes outnumber figurative hunting scenes. ${ }^{632}$ But despite attempts at compiling figure-type catalogues as for sigillata, the manual application of barbotine and the continued experimentation ${ }^{633}$ resulted in unique figures. ${ }^{634}$

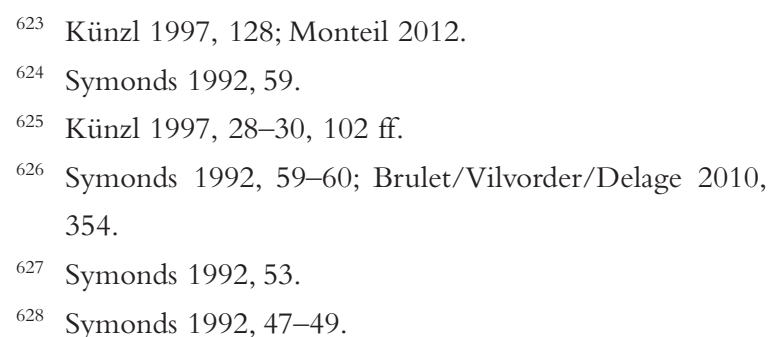

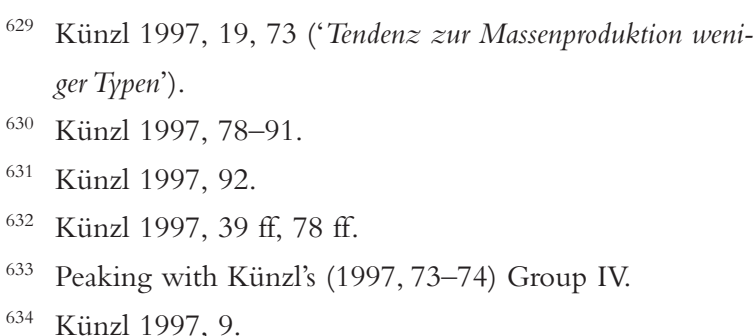




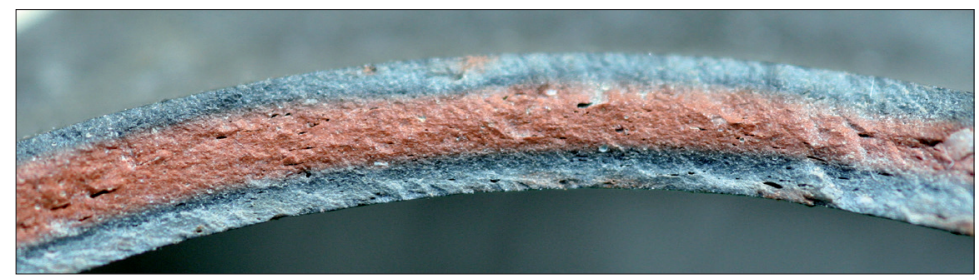

Fig. 5.6. Fabric of Trier 'Rhenish' wares (3rd century AD). (C) Centre de Recherches d'Archéologie Nationale, UCL. From Brulet/Vilvorder/Delage 2010, 352 (with permission).

'Rhenish' wares thus escaped the defining orbit of sigillata, and became the focus of attention in the Trier ceramic production landscape. Nevertheless, this interpretation does not imply a straightforward switch in predefined, static roles. 'Rhenish' ware did not become the new 'category': considerable variation characterized its technological choices, it was not defined by a limited package of traits, nor was it clearly separate from other production sequences. But if they were not defined as a 'category', and no longer functioned as sigillata's 'Other', then how to describe Trier 'Rhenish' wares?

\section{$5 \cdot 2 \cdot 7^{\prime}$ R O O TED' TH INGS}

Trier 'Rhenish' wares are renowned for the high quality of their slips ${ }^{635}$, a result of special care and skill deployed in firing. This created a 'sandwich effect' whereby the red inner core of the fabric is sided by two grey bands right underneath the slip (Fig. 5.6) ${ }^{636}$ This pattern is unique to Trier and points to a specific process of manipulating clay and firing. The fact that it characterizes all Trier 'Rhenish' wares highlights the connectedness of the community of practice at Trier that was already suggested by the spatial organisation of the production site.

The special care attributed to firing and slips did not preclude the recurrent manifestation of fingerprints on finished 'Rhenish' ware vessels, which were much more common than they had ever been on sigillata. ${ }^{637}$ It follows that the indexes of the physical and individual handling of the vessel did not need to be filtered away. The emphasis was on individual skill rather than repetition, and the contingency of the production practices was a defining characteristic (in contrast to the 'category' of sigillata in 2nd century Lezoux).

The product of 'Rhenish' wares was not only firmly anchored in the physicality of its production process, but also in the locality of its production site. With regard to the form repertoire, Symonds hypothesized that a number of short-lived forms were not favoured in the local market and hence preferentially exported. ${ }^{638}$ Even though other reasons may be listed to account for this pattern (e.g. the geographical limits of Symonds' sample) it does at the very least highlight the absence of global norms as to what 'Rhenish' ware pots should look like and what they could not look like. If anything, it seems that such norms were predominantly (or only) enacted at Trier itself, where also the most elaborate specimens ${ }^{639}$ and the greatest variety of forms were found. Other sites yielding Trier imports tapped into a limited repertoire: at Lyon for example Trier beakers were of form Niederbieber 33 only. ${ }^{640}$ This local anchorage of 'what was appropriate' is further emphasized by the fact that the most popular drinking form of Cologne colour-coated wares (with which 'Rhenish' wares had many similarities) - the so-called hunt cup - was not appropriated by the repertoire of Trier 'Rhenish' wares ${ }^{641}$

635 Bocquet 1999, 181; Symonds 1992, 46.

636 Symonds 1992, 49; Brulet/Vilvorder/Delage 2010, 352.

637 Symonds 1992, 49; Künzl 1997, 93.

638 E.g. form 5: Symonds 1992, 55 and passim.
639 Symonds in Brulet/Symonds/Vilvorder 1999, 408.

640 Desbat/Picon 1996.

641 Harris 1986, 106. 
A similar 'local' logic drives the issue of what was being contained in those 'Rhenish' ware vessels used in a drinking activity: beer or wine. ${ }^{642}$ The Treveri and neighbouring tribes had been producing beer in the region ${ }^{643}$, while wine had to be imported before the 3rd century AD, presumably from South Gaul - although precise provenancing still awaits detailed analysis of the amphorae. ${ }^{644}$ From the 3rd century onwards, however, wine cultivation along the Mosel can be inferred on the basis of large vine presses. Hence, during the period when 'Rhenish' ware production enacted a local set of norms, both its possible types of contents - beer and wine - were being locally produced and anchored in agricultural regimes, dietary norms and consumption practices.

The mottoes on 'Rhenish' ware beakers offer more insight into this enactment of local ties (Fig. 5.3). The most common mottoes are VIVAS and MISCE, and overall the repertoire spans the realms of the pub, the whorehouse, and religion. ${ }^{645}$ Harris reminds us that these different themes need not necessarily be seen as distinct: wine, drinking and libations were an integral part of funerary and religious experience. ${ }^{646}$ The chronological trend is towards a reduction in the number of different mottoes in use. ${ }^{647}$ But most importantly, often a direct conversational mode is implied, between bartender and customer, vessel and consumer, pimp and girl, or devotee and religious figure. By 'speaking to' someone, the vessels and their producers actively created ties and relations within a close, locally based range. Sometimes the message was even of a personal character, as in greetings. Moreover, it is possible that some mottoes were commissioned. Adjustment between the number of indentations or impressions in a bowl and the number of letters in the motto ${ }^{648}$ suggests an integrated process of modelling and decorating. ${ }^{649}$ Harris reconstructs the sequence as follows: 'the inscription was put on first, then the spacers and further decoration, with the appliqués apparently added at the end' ${ }^{650}$ So commissioning did not involve the production of 'Halffabrikaten' to be adjusted to the costumer's demands, but instead took place at the very start of the production sequence.

A number of clever wordplays must have required in-depth knowledge of Latin, both on the part of the painter/potter and the consumer. Moreover, the puns and jokes rendered in some of the mottoes were anchored in the local knowledge system at Trier - that of the community of practice of potters and the different intersecting communities in the adjacent city centre (merchants, bartenders, soldiers etc.). One example reads BIBERT[AS] and has been linked to a passage in which Suetonius ${ }^{651}$ relates that the emperor Tiberius received the nickname Biberius Caldius Mero upon entrance in the army, referring to his ability to drink warm and undiluted wine ${ }^{652}$. Such a reading would have been evident within a community in close interaction with the soldiers stationed along the Rhine. So, in summary, the mottoes - more or less unique to Trier ${ }^{633}$ - again hint at a local understanding of 'Rhenish' wares with puns and jokes firmly anchored in the local knowledge system, with a more direct feedback loop between consumption and production than that of sigillata, and with a more coherent community of practice. The physicality of the process of writing mottoes as compared to that of stamping sigillata feeds

${ }^{642}$ Symonds (1992) argues that decorative details distinguish between wine and beer, while Künzl $(1997,96)$ notes that the mottoes mention wine much more often. Both arguments are debatable.

${ }^{643}$ Luik 2001, 269; Binsfeld 1972a. Binsfeld (1972b) builds on an inscription mentioning a female beer (and pottery?) trader - but this reading and the authenticity of the inscription are debated. Wightman $(1970,189)$ cites inconclusive evidence in favour of earlier (late 1st century $\mathrm{AD})$ wine production along the Mosel.

644 Luik 2001, 269.

645 Künzl 1997, 95 ff.
646 Harris 1986.

647 Künzl 1997, 97.

648 Künzl 1997, 92.

649 Contra Symonds 1992, 48 and Künzl 1997, 120 who argue that blank pots were 'customized' by specialist decorators.

650 Harris 1986, 109-110.

651 Suetonius, Tiberius 42.

652 Künzl 1997, 95.

653 Künzl 1997 lists other ceramic products carrying 'mottoes', but these are spread over a large spatiotemporal area and generally only yield a few examples. 


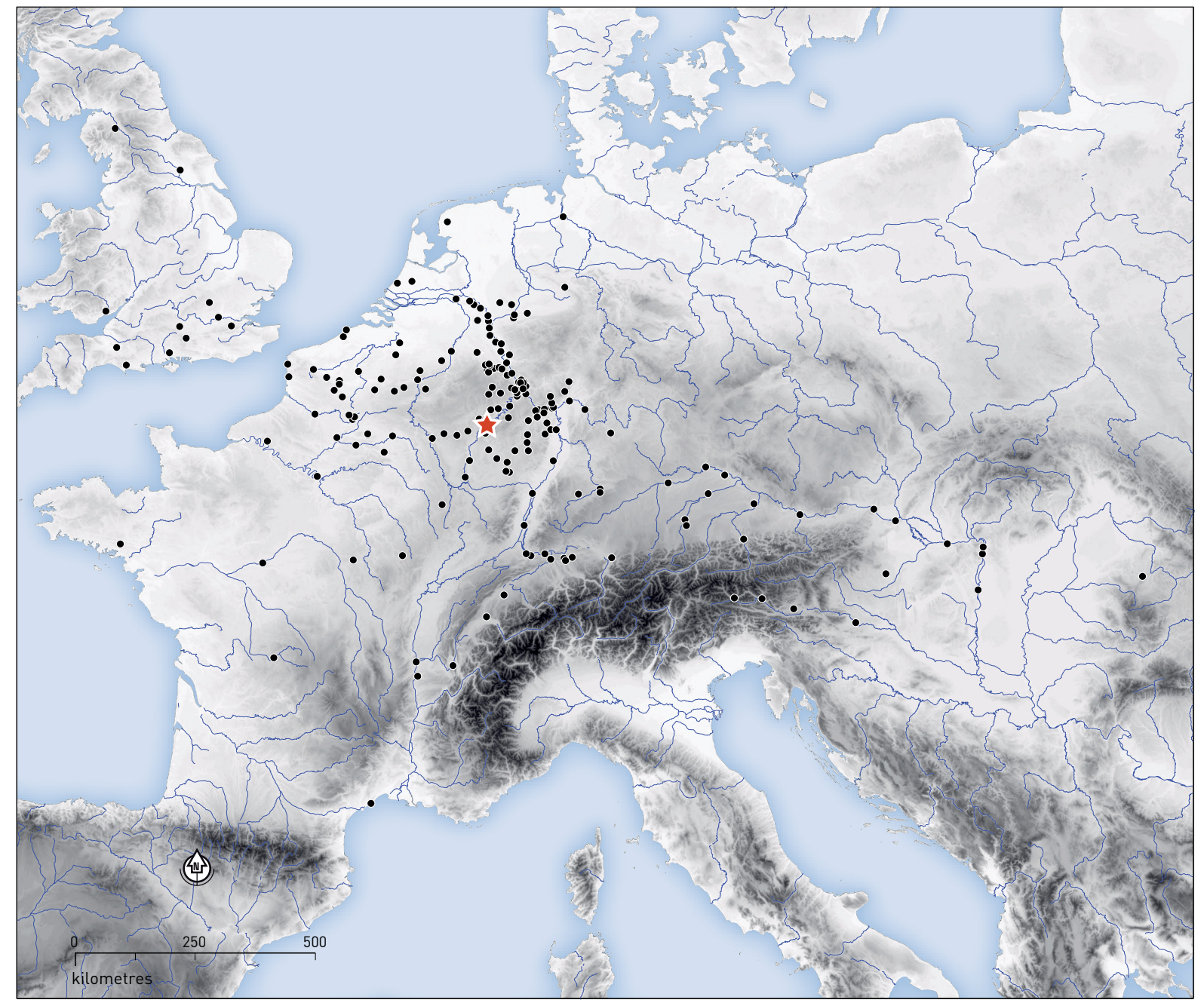

Fig. 5.7. Distribution map of Trier 'Rhenish' wares (3rd century AD). Based on data in Künzl 1997.

into this interpretation: a closer, more direct engagement of the skilled potter was readily made visible. Hence, in a similar vein as with the visible fingerprints indexing physical manipulation, a number of errors in the writing and use of Latin attest to direct handling by individual actors and to local language use and pronunciation. ${ }^{654}$

All of the above technological choices entertain a relation to Trier as an experienced and conceptual locality: the physicality of production, the community of potters and consumers, the routines (e.g. agriculture) and occasional events (e.g. military). This entanglement leads me to suggest the term 'rooted' as an apt description of how 3rd century Trier 'Rhenish' wares were defined, and what they were understood to do. Trier 'Rhenish' wares were rooted in the locality and physicality of their production.

\section{2 .8 D I S T R I B U T I O N}

Trier had easy access to transport infrastructure, by road (Trier-Bavay-Tournai-Kassel) and by river (Mosel and Rhine). The general distribution area of Trier sigillata ${ }^{655}$ covered the limes north of the Main,

654 Harris 1986, 109.

655 Werkstatt I products reached Germania Superior south of the river Main, an area later taken over by Rheinzabern (Huld-Zetsche 1972, 78-79). 


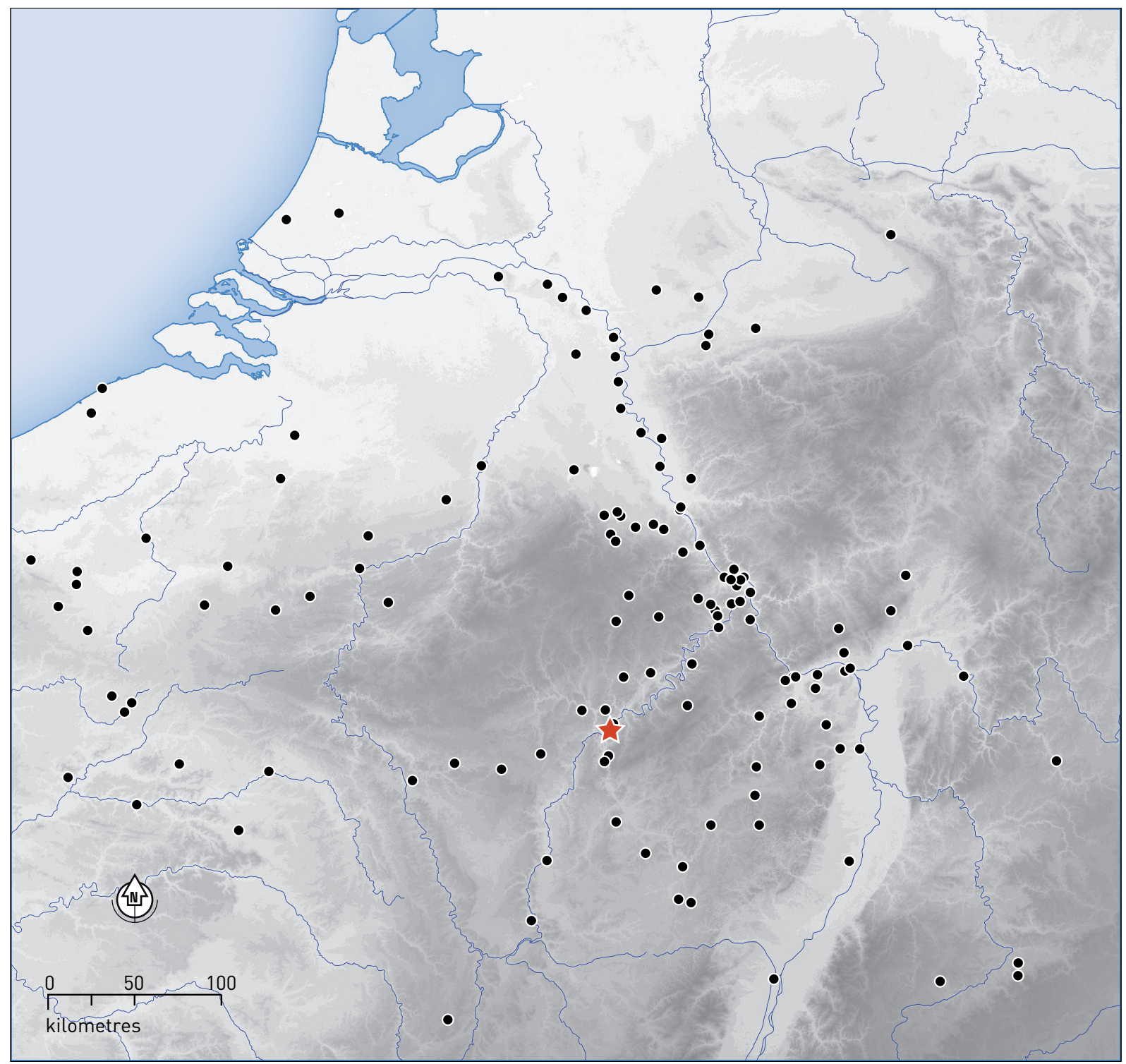

Fig. 5.8. Regional distribution of Trier 'Rhenish' wares (3rd century AD). Based on data in Künzl 1997.

running along the Rhine up to its estuary at the North Sea coast in Holland, and even crossing to Britain. Despite the success of 'Rhenish' wares, sigillata maintained a firm position along the major axes of distribution, in all likelihood accompanying the exports of 'Rhenish' wares. ${ }^{656}$ This is yet another indication of shifting directionality between both production sequences.

'Rhenish' wares had a larger distribution area than Trier sigillata, which leads Künzl to suggest that motto beakers travelled as souvenirs (Figs 5.7 and 5.8) ${ }^{657}$ Even if this sketches a somewhat romantic picture, it highlights the importance of social ties in the organisation of 'Rhenish' ware production at Trier. The discussion above already hinted at a close feedback loop between production and consumption, with the possibility of production to individual order.

Finally, a privileged distribution axis existed between Trier and Lyon ${ }^{658}$, but few 'Rhenish' wares have been found in between these centres. ${ }^{699}$ This direct trade link beyond the "normal' reach of Trier prod-

${ }^{656}$ Brulet/Vilvorder/Delage 2010, 198.

657 Künzl 1997, 112.

658 Desbat/Picon 1996; Desbat/Godard 1999; Desbat/Vil- vorder 2000, 184.

659 Discussion in Brulet/Symonds/Vilvorder 1999, 407. 
ucts emphasizes the importance of specific institutional relations (social, political, and administrative) in shaping the production and distribution of 'Rhenish' wares. Such ties are hinted at by a number of inscriptions found at Lyon that mention merchants originating from Trier but residing in Lyon. Krier recorded 13 inscriptions of Treveri at Lyon, 4 of which referred to merchants. ${ }^{660}$ Wine traders with ties to associations of shippers operating on the Saône are mentioned from the beginning of the 2nd century onwards - about a century prior to the first attestations of wine production at Trier - and would have been involved in shipment of South Gaulish wine to the northern limes area. One often cited example is a partially preserved inscription referring to a $n[$ ego/tiat $]$ ori vinar $[i o$ et / $\operatorname{art}]$ is cretar $[$ iae $]$, a trader of wine and pottery ${ }^{661}$ Interestingly, the top register of the epitaph is decorated with a number of ceramic pots that look like jugs but have been tentatively linked by some (e.g. Loeschcke) to 'Rhenish' wares. Krier undermines this association by dating the inscription to AD 125-150 - prior to the start of 'Rhenish' ware production at Trier. ${ }^{662}$ But Krier's dating is far from secure, and others have extended the possible date range of the inscription from the middle of the 2nd to the middle of the 3 rd century, which would draw it within chronological reach of Trier 'Rhenish' ware production. ${ }^{663}$

Although the jury is still out on this example, the extraordinary number of attestations of merchants with links to both Trier and Lyon highlights the importance of social ties, networks of knowledge and communities of practice through which information was circulated and mediated. In this case a privileged link was established between two provincial capitals (Trier and Lyon), and was thus anchored in the structure of empire. But the observation that the vessels exported to Lyon were not the most elaborate examples (which were found at Trier itself) underscores the local discourse of 'Rhenish' ware production at Trier.

\section{2 .9 RELATIONS A N D ROOTS}

A phase of initial sigillata production at Trier (from ca. AD 130 onwards) did not tap into the Central Gaulish production practices discussed in the previous chapters. Consequently, the conditions of evaluation of the Central Gaulish 'category' of sigillata did not hold true: whereas sigillata vessels of this period attained a high quality, their fabrics used the same non-calcareous clays as a series of other products, their moulds were not signed, etc.

Given the rather imprecise chronological framework covering the end of the 2nd and the beginning of the 3rd century AD in the region under study, it is difficult to ascertain the relation between technological changes observed for sigillata production (calcareous clays, signed moulds, new decorative schemes etc.) and the introduction of 'Rhenish' ware production at Trier. By focusing on the longer history of the different technological changes, however, this study makes a case for the introduction of Central Gaulish practices of sigillata production. The previous section discussed how a 'category' is defined on its own, as separate from other things, only through its relations of difference with those other things. In the case of Lezoux sigillata, the most explicit 'Other' was 'Rhenish' ware production. To assure the transmission of sigillata production practices as a 'category', their 'Other' - 'Rhenish' ware production - had to keep defining the boundaries of 'what (did not) count(ed) as sigillata'. Hence the 'Other' facilitated the global circulation of the 'category', allowing its production to be replicated at sites beyond Lezoux. ${ }^{664}$ But this exercise of replication - of keeping sigillata's package of traits stable and well-defined - demanded a lot of effort.

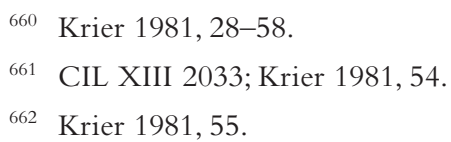

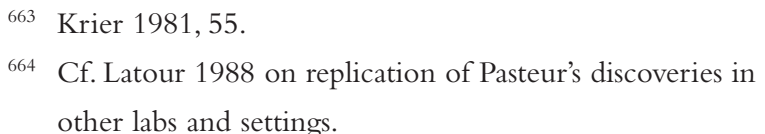


We can only speculate on the involvement of further agencies in this process:Trier was a city whose existence and make-up had been arranged by imperial authorities (e.g. road link with Lyon established by Agrippa), and where commercial interests intersected with political and military strategy (due to its location near the northern frontier zone). But the boundaries defining sigillata production at Lezoux did not persist long beyond initial transmission to Trier, and the 'category' they circumscribed dissolved. Sigillata production practices became open-ended and less rigidly defined, underscoring the fragility of a 'category', and the need for constant reaffirmation.

Meanwhile, 'Rhenish' ware production escaped its role as sigillata's 'Other' and was singled out through special attention for and segregation of a number of its production stages. Whereas the relation with sigillata remained articulated, its directionality shifted somewhere along this process: 'Rhenish' wares were no longer defined in relation to sigillata. Nevertheless this does not imply a straightforward switch between 'Rhenish' wares and sigillata whereby the latter simply took on the former's role as a homogeneous, bounded category.

Rather, 'Rhenish' ware production remained fundamentally anchored in the local practices at Trier. Such an experience of 'localness' was created in a number of ways: the spatial unity of the production area and the intense communication this would have entailed; the emphasis on the physicality of individual skill evident for instance in the traces of fingerprints and in the rendering of barbotine decoration and mottoes; the specific mixed geological signature of the clays around Trier; the puns woven into the mottoes which would have been fully comprehensible only to an 'insider' audience; the restriction of the most elaborate pieces and special forms to Trier itself; the directional links of distribution based on the administrative role of Trier and the personal ties of its citizens; etc. In other words, 'Rhenish' wares remained entangled with the contingencies of who they were produced by, where, how, etc. I introduced the metaphor of a 'rooted' thing to denote local entanglement as explicit and fundamental to the definition of a thing and its possibilities.

\subsection{THING-ThING RELATIONSAND HISTORICAL CHANGE}

At the end of chapter 3, terra sigillata had become defined as a homogeneous, bounded category in production at Lezoux. This may make cynics doubt whether the narrative presented here is all that different from traditional, retrospective accounts. After all, the end result is the same - standardized sigillata. Put differently, the starting point of retrospective historical accounts has been questioned, but has been confirmed! No reason not to continue the way we sort sigillata, the way we publish it, or the way we use it as historical evidence for cultural and economic reconstructions?

Sigillata did indeed become a separate category, which makes its study today amenable to specialisation. But this chapter has argued that keeping the category of sigillata separate was a work in progress, which was never finished. Paradoxically, keeping sigillata unrelated to other production sequences depended on maintaining its relations of difference to those production sequences, in particular that of 'Rhenish' wares. Each of the technological choices for 'Rhenish' wares referred to sigillata and emphasized their difference.

This has repercussions for how we process, analyse, and study terra sigillata. This is not to say that typologies are wrong, and that we should never have sigillata processed separately by a specialist. But the relation between sigillata and 'Rhenish' wares does make us aware of the need to retain flexibility between artefact classes at every stage of their analysis and interpretation. If boundaries were contingently constructed in the past and could well have been constructed differently, then the same goes for the present.

More emphasis has to be put on thing-thing relations, relations between different 'classes' of artefacts. Such a call is not new for archaeology ${ }^{665}$, but the mutually defining relation between sigillata and 'Rhen- 
ish' wares shows that it needs to be extended beyond relations of direct causal or semantic dependency. While it is clear that clay depends on water, or cups need saucers, the mutual dependency between a category and its 'Other' stretches thing-thing relations into the conceptual domain. Nevertheless, the relation is still based on practice; in this case, on the practical similarities and differences between the production sequences of sigillata and 'Rhenish' wares. And just like the presence of water shapes the possibilities for clay to be formed into a pot, the relation with its 'Other' was crucial for sigillata to remain a category, and to maintain its possibilities for competition and exchange as discussed above.

Neglecting thing-thing relations has an impact on the kinds of historical narratives we can build on the basis of terra sigillata too. For instance, this chapter discussed that sigillata produced at Trier in the 3rd century no longer ticked all the boxes set by the Central Gaulish template. In a retrospective framework, it is tempting to link this observation to a supposed 'degeneration' of craftsmanship or production organisation, on a par with changed historical conditions, and a degeneration of Roman imperial culture itself. Such narratives of 'decadence' or 'failure' have implicitly moulded our approach to for instance the 3 rd century in the northwestern provinces, subject to administrative reorganisation and Germanic incursions. Behind such interpretations lurks a problematic value judgment. But even more problematic is the fact that these value judgments are spurred by the use of a universal template of the category of sigillata as yardstick for empirical analysis. Third century Trier sigillata cannot but seem degenerate compared to a notional ideal of standardized sigillata with calcareous clays, shiny slips and a limited form repertoire, clearly separate from other products. This notional ideal can now be taken for what it was: a historically contingent development at 2nd century Lezoux. Third century Trier sigillata had cut its historical links with this development, and was no longer defined as a homogeneous and bounded category. Instead of locating the causal factors for this process in 'failing' external actors ('who', again: consumers, producers, investors, etc.), this can be rephrased as a shuffling of the relations between things - in this case between sigillata and 'Rhenish' wares. Again, acknowledging things and relations between things as history-makers will improve their use as history-tellers, leading to better historical narratives.

In a non-retrospective approach to material culture, not everything is a priori defined as a category. ${ }^{666}$ In this chapter, we have encountered Lezoux 'Rhenish' wares as a category's 'Other', maintaining the boundaries of the sigillata production sequence but not itself strictly bounded and homogeneous in its technological choices. As sigillata's 'Other', 'Rhenish' wares facilitated the former's transmission as-is (with the same package of traits and separate from other products) to other production sites, such as Trier. A couple of decades later, the relation shifted direction: increasing attention was paid to the 'Rhenish' ware production sequence, whereas sigillata's package of traits was loosened. Characterised by a large latitude of variation in technological choices and a lack of clear-cut boundaries, 'Rhenish' wares became defined through emphasis on the locality and the physicality of the production process. As 'rooted' things they created different possibilities for action compared to both the homogeneous category of 2 nd century Lezoux sigillata and its 'Other' of Lezoux 'Rhenish' wares. How exactly did these possibilities differ for distribution and consumption? And how did these shape different historical trajectories? This is the question that the next chapter will tackle. 
